\title{
An Evaluation of Online Pharmacies for Compliance to Regulatory Criteria and Price Variation of Listed Medicines
}

\author{
Chetan Dasharathbhai Parikh*, Chetna Kalpan Desai, Megha Kiritkumar Shah, Vishal Rameshchandra Mishra \\ Department of Pharmacology, B.J. Medical College, Ahmedabad, Gujarat, INDIA.
}

\begin{abstract}
Objective: To evaluate Online Pharmacies (OPs) for compliance to regulatory recommendations and to assess price variations of selected medicines, sold from these pharmacies. Method: The first 100 listed websites from different countries on Google (Search terms: "e-pharmacy websites" and "online pharmacies") were selected. Primary and secondary criteria for assessment were determined from Verified Internet Pharmacy Practice Sites (VIPPS) programme and recommendations of relevant regulatory bodies. A checklist was prepared and re-validated. The OPs were grouped according to the presence of regulatory recommendations in that country. Seven branded medicines sold in India were selected and assessed for price variations. Results: A total of 100 OPs belonging to 17 different countries were analyzed. Of these, 32 were Indian. Forty-seven OPs from countries with regulatory recommendations for OPs were included in Group- A. Of these, 24 (51\%) OPs did not comply with primary criteria like Shipment within territory of the country $(60 \%)$, requirement of prescription (39\%), confidentiality policy (34\%) and secondary criteria like providing option for communication with pharmacist $(43 \%)$, toll-free number $(39 \%)$ and information about contraindications and special precautions (65\%). Fifty-three
\end{abstract}

OPs belonged to countries without any regulatory recommendations made for OPs and were included in Group- B. Of these 16 OPs did comply with the criteria. About 40\% OPs provide a facility for a prescription refill. An option for generic/lower price substitute was provided in 79\% OPs. A marked price variation (14\%-32\%) was observed for selected brand medicines. Conclusion: Continuous monitoring for adherence to regulatory recommendations, price variations and consumer education about the appropriate use of OPs is required.

Key words: E-pharmacy websites, Internet pharmacy, Online health screening, Online pharmacies, Prescription refill, VIPPS (Verified Internet Pharmacy Practice Sites).

\section{Correspondence}

Dr. Chetan Parikh, Third Year Resident, Department of Pharmacology, B.J. Medical College, Ahmedabad, Gujarat- 380016, INDIA.

Phone: +919724488904

Email: cparikh09@gmail.com

DOI: 10.5530/jyp.2019.11.43

\section{INTRODUCTION}

Online pharmacies are websites for purchasing medicines through the internet. They are also named as cyber pharmacy, E-pharmacy, internet pharmacy or virtual pharmacy. These are of three types. Most of the online pharmacies only served as a medium between customers and physical pharmacy stores. They can be termed as Independent online pharmacies. Some physical pharmacy stores extend their service to the "online world" for the growth of their business. They are the online extension of physical pharmacies. Remaining online pharmacies represent a partnership of two or more physical pharmacies. ${ }^{1}$

The popularity of online pharmacies is increasing day by day as they provide home delivery, convenient shopping, accessibility, wider choice, reduction in time and effort of shopping. ${ }^{2}$ Refill reminder is a good service from online pharmacies in which the pharmacies send alerts regarding the refill of the prescription. They are particularly convenient to the geriatric patients or patients suffering from chronic conditions who are required to buy or refill medicines frequently. Online pharmacies sell a very wide range of products including Over the Counter (OTC) medicines, prescription-only medicines, medical devices, pet medicines, herbal products and beauty products.

In India and in other countries, where there are no regulatory guidelines for online pharmacies, there are possibilities of misconduct like selling prescription-only medicines without a prescription, counterfeit medicines, abuse liability medicines, inadequate provision of sufficient and necessary information and counselling about the medicines. Anti-depressants, anti-anxiety medications, anti-obesity drugs, sildenafil citrate containing medicines can be easily obtained from some internationally shipping online pharmacies. The customers are also misguided about the source of the country from where the medicines are being shipped. ${ }^{3,4}$ Further, there are some ethical issues in using the internet as a medium to buy medicines. As online pharmacies require consumers to submit the confidential medical information, the confidentiality and privacy of consumers are at stake. Also, the security of the online transaction is a big concern for consumers. ${ }^{5,6}$

In 1999, the National Association of Boards of Pharmacy (NABP) had created a voluntary program "Verified Internet Pharmacy Practice Sites (VIPPS)" to certify the online pharmacies in the USA. ${ }^{5}$ There are other country-specific regulatory bodies like General Pharmaceutical Council $(\mathrm{GPhC})$ in the United Kingdom and Canadian International Pharmacy Association (CIPA) in Canada. They set some definite criteria to which online pharmacies should comply with. On application from an online pharmacy, they analyze the website for the criteria. Online pharmacies, which fulfil the criteria, are hyperlinked with the logo of the regulatory body. So, the logo confirms the authenticity of the online pharmacy site. If the websites do not comply with the VIPPS program, the certification may get suspended. ${ }^{7,8}$ The criteria differ for different countries but there are some common criteria like the requirement of a registration or a license, registered staff, maintenance and enforcement of confidentiality policy, verification of the identity of patient and prescriber, the requirement of a prescription for prescription-only medicines and maintenance of storage and shipping methods etc., ${ }^{910}$ 
In developing countries like India, the price of medicine is an important consideration while purchasing medicines. Brand medicines are the drug molecules developed by a pharmaceutical company after years of research. These are patented for a defined number of years depending on the country's regulations. After the expiry of the patent, other pharmaceutical companies make the copy of the brand drug containing the same active ingredient. This is known as the branded generic medicine. The price of brand medicines usually is higher than branded generic drugs. ${ }^{11}$ There is a wide variation in the price for different brands of the same medicine. Online pharmacies generally provide a cost benefit to consumers, as the prices of medicines sold by OPs are lower than those sold by the physical pharmacies. ${ }^{3}$ However, the medicine of similar brand might be sold with different prices in different online pharmacies. There are some studies that focus on the availability of "prescription-only medicines" without a prescription and compliance with regulatory criteria in western countries. ${ }^{12,13}$ However, there was no Indian study which has evaluated the compliance of regulatory criteria by online pharmacies. Hence, this study aims to evaluate online pharmacy websites for compliance with regulatory criteria and to compare the prices of the selected medicines sold by these pharmacies.

\section{MATERIALS AND METHODS}

This was an observational analytical study. The source of data was the internet. The first 100 websites from different countries listed in Google after entering the search term "e-pharmacy websites" and "online pharmacies" were chosen for the study. Primary and secondary criteria for evaluation of these websites were determined on the basis of VIPPS programme guidelines and recommendations of other relevant regulatory bodies for those respective countries. We have selected the criteria according to their importance in promoting rational use of medicines, preventing misconduct and likeness of recommendation among different regulatory bodies. Primary criteria for evaluation included: shipment within the territory of the country, availability of a retail license, display of contact address, display of privacy policy, the requirement of prescription, confidentiality policy, displaying instruction for use of the drug, side effects of drugs and the use of online health screening were the primary criteria. Option for communication with the pharmacist for any medicine related query, provision of a toll-free number, displaying a list of generic substitutes for brand medicine, providing information about contraindications and special precautions for the medicine were secondary criteria used in the study. There were some additional criteria like the mention of storage conditions in shipment policy, mention of manufacturing and expiry dates of the medicine, last date of updating webpage etc.

All 100 websites were evaluated for adherence to the selected criteria and the data were entered into the excel sheet as "Yes" or "No" in regard to compliance or non-compliance with the given criterion. Online pharmacies which belonged to countries with the presence of regulatory recommendations for online pharmacies were included in Group A and online pharmacies which belonged to countries without regulatory recommendations for online pharmacies were included in Group B. Compliance to regulatory criteria was compared between these two groups. Seven brand medicines were selected according to their frequency of online order, the inclusion of different drug groups and drugs used for chronic disorders. Cap. Mox500 (Amoxicillin 500mg), Tab. Azee (Azithromycin $500 \mathrm{mg}$ ), Tab. Voveran (Diclofenac 50mg), Tab. Thyronorm (Levothyroxine $100 \mathrm{mcg}$ ), Tab. Diproex (Sodium valproate 500mg), Tab. Zincovit (Vitamin A 5000IU, Vitamin D3 400IU, Vitamin B2 10mg, Vitamin B6 $2 \mathrm{mg}$, Vitamin C 75mg, Vitamin B5 10mg, Vitamin B1 10mg, Niacinamide 50mg, Magnesium 18mg, Copper 0.5mg, Manganese 0.9mg, Zinc $22 \mathrm{mg}$, Selenium $50 \mathrm{mcg}$, Folic acid $1 \mathrm{mg}$, Biotin $150 \mathrm{mcg}$, Iodine $150 \mathrm{mcg}$,
Molybdenum 25mcg, Vitamin E $15 \mathrm{mg}$ ), Inj. Human mixtard $10 \mathrm{ml}$ vial 40IU/ml (Regular Insulin 30\%+ Insulin Isophane 70\%) were selected for evaluating the price variation among different Indian online pharmacies. Percentage of price variation was calculated as follows:

Percentage of price variation $=($ maximum cost - minimum cost $/ \mathrm{maxi}-$ mum price) ${ }^{*} 100$

The statistical analysis was done by Fischer's exact test.

\section{RESULTS}

A total of 100 online pharmacies were evaluated during the study. Ninety-six of these belonged to 17 different countries. Information regarding the country to which they belong to was not mentioned for four online pharmacies.

The most deficient primary criterion observed was information about the side effects of medicines (Figure 1). Information regarding the sideeffects of medicines was not mentioned in $27 \%$ of online pharmacies. Twenty-three per cent online pharmacies included a questionnaire or gave the option of an online consultation with the "cyber doctor". Most of the online pharmacies had a retail license. Twenty-four per cent online pharmacies were shipping outside their nation's territory.

'Special precautions regarding the use of the medicine' was the most deficient secondary criterion, which was not followed by $53 \%$ online pharmacies (Figure 2).

There should be an option to select medicine from other brand or generic medicine for the prescribed medicine, but $21 \%$ online pharmacies did not follow this criterion.

Twenty-six per cent online pharmacies did not reveal their contact address that would strengthen their authenticity. Sixteen per cent online pharmacies did not ask for purchasing medicines.

Total 47 online pharmacies were from the countries with regulatory body criteria for these pharmacies (group A). From group A, 24 online pharmacies (Nine from the UK, 8 from Canada, 6 from the USA, 1 from Germany) did not comply with most of the primary and secondary criteria. The major deficient criteria were shipping outside the territory of the nation (14), display of information regarding special precaution (10) and non-availability of toll-free number (9). Four online pharmacies of Canada which did not comply with the criteria, had no logo of CIPA on their homepage while 4 online pharmacies had the logo. These online pharmacies from the USA did not have VIPPS logo on their homepage. Remaining 23 online pharmacies did comply with these criteria (Table 1 and 2).

From group B, 16 online pharmacies did comply with the criteria (India-12, Australia-3 and New Zealand -1). The major deficient criteria in group B online pharmacies were display of information regarding

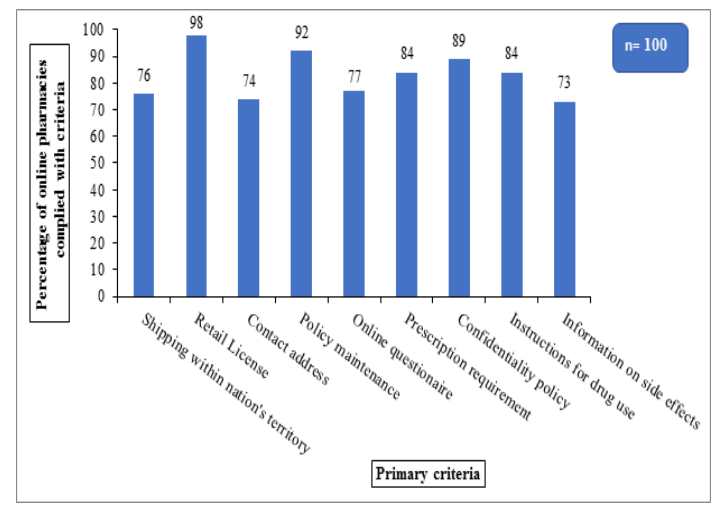

Figure 1: Compliance to Primary Regulatory Criteria by Online Pharmacies. 
special precautions and contraindications of medicines (28 and 26, respectively), provision of a toll-free number (17), provision of option to communicate with the pharmacist (15) and giving online questionnaire for sale of medicines (16). Both the groups were significantly different in adherence to criteria like shipping within nation's territory $(p<0.001)$, use of an online questionnaire ( $p=0.009$ ), display of instructions for drug use $(p=0.002)$ and display of contraindications of medicines $(p=0.003)$ (Table 2).

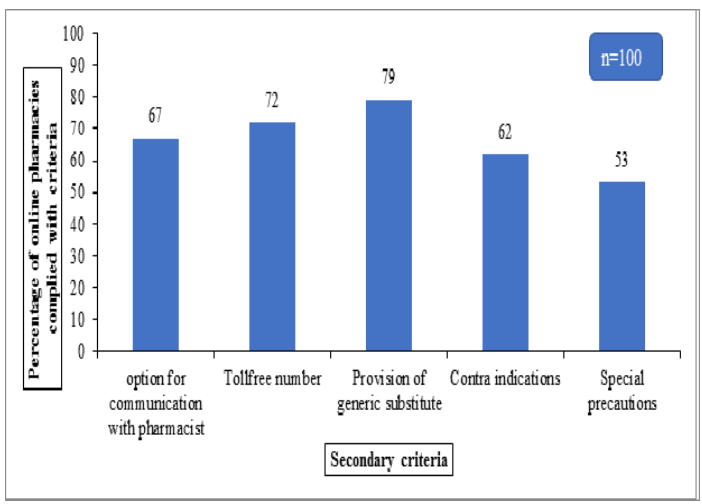

Figure 2: : Compliance to Secondary Regulatory Criteria by Online Pharmacies.
There was a high variation in the price of seven selected brand medicines (14-32\%) (Figure 3). The maximum price variation (32\%) was observed for the Cap. Mox500 (Amoxicillin 500mg). The minimum price variation (14\%) was observed for Tab. Voveran (diclofenac 50mg).

\section{Additional Information}

From the total 100 online pharmacies, 82 were independent online pharmacies. Eighteen online pharmacies were a branch of the physical pharmacy store. None of the online pharmacy stores required submission of the identity proof of the patient/customer as a prerequisite for purchase.

The login details required were personal information and cell phone number/ email address. No document regarding the identity proof or residential proof was requested for authentication of identity. This could lead to discrepancies in the usage of medicines. None of the online pharmacies mentioned temperature, light and humidity conditions required to be maintained during shipment in the policy.

No online pharmacy has mentioned expiry date, manufacturing date and batch number of medicines ordered. Twenty-one online pharmacies gave the option to upload health information. Twenty-five online pharmacies had given the information regarding the treatment in overdosing of medicine. None of them mentioned the last date of updating of the webpage. The provision of prescription refill was given in $40 \%$ online pharmacies. Twenty-five per cent online pharmacies had given the information regarding the treatment in overdosing of medicine.

Table 1: Country-Specific Evaluation of Online Pharmacies.

\begin{tabular}{|c|c|c|c|c|c|}
\hline Sr. No. & Country & $\begin{array}{l}\text { Total number of Online } \\
\text { pharmacies evaluated } \\
\qquad(n=100)\end{array}$ & $\begin{array}{l}\text { Local regulatory body } \\
\text { present or not? }\end{array}$ & $\begin{array}{l}\text { Number of stores that } \\
\text { complied with criteria }\end{array}$ & $\begin{array}{l}\text { Number of stores that did not comply with } \\
\text { criteria }\end{array}$ \\
\hline 1. & India & 32 & No & 12 & 20 \\
\hline 2. & $\begin{array}{l}\text { United } \\
\text { Kingdom }\end{array}$ & 16 & Yes & 7 & 9 \\
\hline 3. & Canada & 15 & Yes & 7 & 8 \\
\hline 4. & $\begin{array}{l}\text { United States } \\
\text { of America }\end{array}$ & 10 & Yes & 4 & 6 \\
\hline 5. & Pakistan & 5 & No & 0 & 5 \\
\hline 6. & Australia & 4 & No & 3 & 1 \\
\hline 7. & Sri Lanka & 2 & No & 0 & 2 \\
\hline 8. & Nepal & 2 & No & 0 & 2 \\
\hline 9. & Ireland & 2 & Yes & 2 & 0 \\
\hline 10. & Singapore & 1 & No & 0 & 1 \\
\hline 11. & Israel & 1 & No & 0 & 1 \\
\hline 12. & $\begin{array}{l}\text { The Czech } \\
\text { Republic }\end{array}$ & 1 & No & 0 & 1 \\
\hline 13. & France & 1 & Yes & 1 & 0 \\
\hline 14. & Germany & 1 & Yes & 0 & 1 \\
\hline 15. & Greece & 1 & Yes & 1 & 0 \\
\hline 16. & New Zealand & 1 & No & 1 & 0 \\
\hline 17. & Egypt & 1 & Yes & 1 & 0 \\
\hline 18. & Not specified & 4 & NA & 0 & 4 \\
\hline
\end{tabular}




\section{DISCUSSION}

As the number and purchase from online pharmacies have been increased, constant monitoring by regulatory bodies is required. According to guidelines of VIPPS "online pharmacies should maintain and enforce policies and procedures that assure the integrity, legitimacy and authenticity of the Prescription Drug Order and seek to prevent Prescription Drug Orders from being submitted, honoured and filled by multiple pharmacies. Online pharmacies should assure that prescription medications are not prescribed or dispensed based upon telephonic, electronic or online medical consultations without there being pre-existing patientprescriber relationships that have included an in-person physical examination. ${ }^{9}$ There are some studies that evaluate the online pharmacies for the availability of prescription-only medicines without prescription and compliance with regulatory criteria in western countries. However, to the best of our knowledge, no Indian study has evaluated the compli-

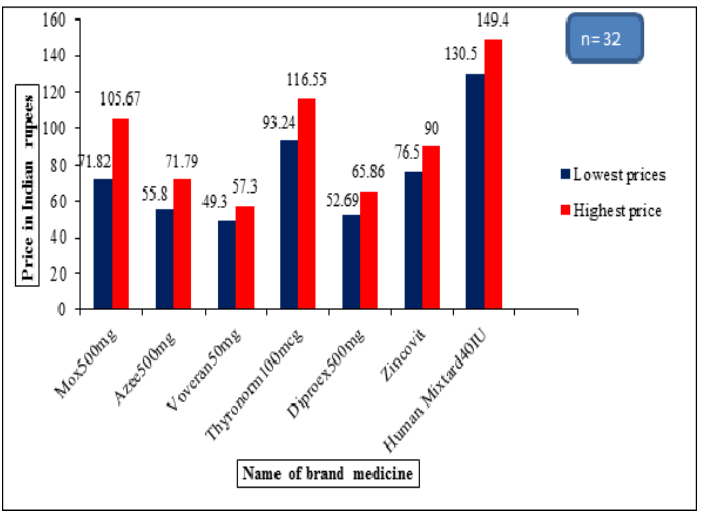

Figure 3: Price Variation of Brand Medicines among INDIAN ONLINE PHARMACIES.

Table 2: Comparison of Compliance of Online Pharmacies to Regulatory Criteria.

\begin{tabular}{|c|c|c|c|c|}
\hline Sr. No. & Criterion & $\begin{array}{l}\text { Number of compliant online } \\
\text { pharmacies in Group A** } \\
\qquad(n=47)\end{array}$ & $\begin{array}{l}\text { Number of compliant online } \\
\text { pharmacies in Group } B^{* * *} \\
\qquad(n=53)\end{array}$ & $P$ \\
\hline 1 & $\begin{array}{l}\text { Shipment within } \\
\text { territory of the } \\
\text { country }\end{array}$ & 28 & 47 & $<0.0011^{\star}$ \\
\hline 2 & Retail License & 47 & 51 & 0.4968 \\
\hline 3 & $\begin{array}{l}\text { Display of contact } \\
\text { address }\end{array}$ & 37 & 41 & 1.0 \\
\hline 4 & $\begin{array}{l}\text { Display of privacy } \\
\text { policy }\end{array}$ & 46 & 46 & 0.063 \\
\hline 5 & $\begin{array}{l}\text { Use of online health } \\
\text { screening }\end{array}$ & 30 & 46 & $0.0097^{*}$ \\
\hline 6 & $\begin{array}{l}\text { Prescription } \\
\text { requirement }\end{array}$ & 39 & 45 & 0.5673 \\
\hline 7 & Confidentiality policy & 45 & 44 & 0.0562 \\
\hline 8 & $\begin{array}{l}\text { Instructions for drug } \\
\text { use }\end{array}$ & 46 & 41 & $0.0023^{*}$ \\
\hline 9 & $\begin{array}{l}\text { Display of medicine's } \\
\text { side effects }\end{array}$ & 40 & 37 & 0.0957 \\
\hline 10 & $\begin{array}{l}\text { option for } \\
\text { communication with } \\
\text { pharmacist }\end{array}$ & 37 & 38 & 0.4913 \\
\hline 11 & Toll free number & 36 & 36 & 0.378 \\
\hline 12 & $\begin{array}{c}\text { Provision of generic } \\
\text { substitute }\end{array}$ & 42 & 42 & 0.185 \\
\hline 13 & $\begin{array}{l}\text { Display of contra } \\
\text { indications }\end{array}$ & 38 & 27 & $0.003^{*}$ \\
\hline 14 & $\begin{array}{l}\text { Display of special } \\
\text { precautions }\end{array}$ & 31 & 25 & 0.071 \\
\hline
\end{tabular}

Statistical significance was determined by Fischer's exact test.

${ }^{*} p$ value $<0.05$ was considered statistically significant.

${ }^{* *}$ Group A includes online pharmacies that belong to the countries with presence of regulatory body.

${ }^{* * *}$ Group B includes online pharmacies that belong to the countries without regulatory body. 
ance of regulatory criteria by online pharmacies. Hence, this study was conducted to evaluate the compliance of online pharmacies to regulatory criteria.

According to guidelines, online pharmacies should provide the physical contact address. In case of any major issues regarding the delivery of medicine which could not be resolved online, consumers can raise their queries by using the contact address. In our study, online pharmacies which provide an address (74\%) was similar to Bessel et al. (82.3\%) and in contrast to Orizio et al. (43.2\%). Bessel and team surveyed total 104 online pharmacies using the Copernic meta-search engine in $2011 .^{13}$ Orizio and colleagues investigated total 118 online pharmacies and analysed their characteristics by content analysis method in $2007 .{ }^{14}$ There were $26 \%$ online pharmacies which did not display physical contact address. Four online pharmacies didn't show information regarding their country of origin. The possibility of unethical practices is high in these OPs. The major focus of these OPs is on the sale of medicines for erectile dysfunction and selling prescription-only medicines without a prescription. Online pharmacies which provide online health screen was (49\%) similar to Bessel et al. (38.1\%) and in contrast to Orizio et al (68.8\%). In the study done by Orizio, 66 out of 118 (68.8\%) online pharmacies required the consumer to fill a medical questionnaire to purchase prescription only medicine, without the need of a prescription. This discrepancy might be due to the fact that Orizio et al. used "content analysis method" for analyzing the information given on the websites. The country to which the OP belongs also, influence the adherence to this criterion because of variation in the presence of regulatory guidelines in different countries. However, they did not collect the data regarding the country of origin of online pharmacies.

The requirement of a valid prescription for selling the medicines online is the most important and the commonest criterion among regulatory recommendations. However, our study revealed that $16 \%$ OPs did not ask for a prescription before buying prescription-only medicines. This finding is similar to the study by Bessell et al. in which 19\% $(n=104)$ sold prescription-only medicines without prescription whereas Orizio et al. showed $81.6 \%$ ( $n=118)$ online pharmacies did not ask for a prescription. The difference in the result might be due to the difference in the methodology. This will lead to haphazard use of medicines by consumers and increase the chances of side effects and drug interactions. Antibiotics and controlled substances are also sold through the internet without prescription which increases the prevalence of antibiotic resistance and drug abuse. ${ }^{15,16}$

There was a variation in adherence to the regulatory criteria between group A and group B. In spite of the presence of local regulatory recommendations, there were twenty-four OPs which did not comply with the criteria. We did not find any seal or verification link of the regulatory body in ten websites. This could be the reason for the less difference observed in the compliance of group A and group B. Alwon et al. observed statistically significant difference in requirement of prescription $(p<0.001)$, display of contact address $(p<0.001)$ and no statistically significant difference in the use of online questionnaire $(p=0.37)$. In our study there was statistically significant difference observed in group A and group B regarding the adherence to criteria like, shipment within the territory of the country $(p<0.001)$, use of online health screening $(p=0.009)$, display of instructions for drug use $(p=0.002)$ and display of contraindications of medicines $(p=0.003)$ and no statistically significant difference was observed in the requirement of prescription $(p=0.56)$ and display of contact address $(p=1.0)$. Alwon and colleagues evaluated the difference between regulated (Those registered and linked with any regulatory body) and non-regulated (Those not registered and linked with any regulatory body) online pharmacies, whereas in the present study the grouping of OPs is based on presence or absence of the regulatory body in the country. Alwon and colleagues considered the OP which displayed the seal of the regulatory body as a regulated OP and others as non-regulated OP. This might be the reason for the contrary results.

According to our literature search, this is the first Indian study evaluating price variations of medicines sold online. Price variation was studied in thirty-two Indian OPs. Maximum price variation was 32\% for Tablet Mox500 (Amoxicillin 500mg). Lowest price variation was 14\% for Tablet Voveran (Diclofenac 50mg). There was a similar study conducted in 2005 showed that branded medicines from Canadian online pharmacies cost $24 \%$ less than U.S. drug chain pharmacies. ${ }^{17}$ The study done in Kolkata by Das SC et al. showed a variation of $7 \%$ to $881 \%$ among different brands of the same medicine in physical pharmacy stores. ${ }^{18}$ The study in Karnataka also showed high price variation (10.89\% to $1040.58 \%)$ in different brands of anti-hypertensive. ${ }^{19}$ So, there was a variation in price in different brands in physical pharmacies. These findings suggest that variations exist in the price of similar brand drugs in online pharmacies.

We observed that $24 \%$ online pharmacies sold the medicines internationally. These online pharmacies pose a higher risk of selling counterfeit medicines and prescription-only medicines without a prescription. The regulations and schedules of drugs are different for different countries. Therefore, some consumers may use these OPs to obtain medicines that are not easily available in their country. No online pharmacy store has mentioned expiry date, manufacturing date and batch number of ordered medicines. This criterion is useful in preventing delivery of expired medicines and counterfeit medicines. The option for a prescription refill was given in $40 \%$ OPs. Prescription refill is very helpful in chronic conditions and for geriatric patients. Especially, for patients taking antidepressants, medication non-adherence can be identified, managed and prevented. ${ }^{20}$ However, this option should be backed up with a restriction on number of times the prescription was refilled. So, the option for prescription refill should be included in regulatory guidelines.

Communication between consumer and pharmacist is necessary for any medicine related query like side effects. In our study, 33\% online pharmacies didn't provide an option for communication with a pharmacist. Holmes et al. observed that the quality of counselling also suffers from low response rates and incomplete information. ${ }^{21}$ There should be clear instructions given on the webpage regarding the storage and transport of medicines. We observed that there was no online pharmacy, which mentioned the maintenance of appropriate temperature, light and humidity during shipment.

As the information regarding medicines and regulations were constantly changing, the online pharmacies should update their webpage, as and when required. However, in our study, no online pharmacy store has given the last date of update for the webpage. The consumers have the right to know how recent the information in the online pharmacy is! In our study, only eight online pharmacies had displayed the year in which the website was launched.

This study has certain limitations. For example, we have only included the first 100 websites listed in Google. We could not include all regulatory criteria, for example, criteria regarding checking the registration status of staff, policy regarding the undue delay in delivery of medicines and maintenance of quality assurance program were not included in the study. Nonetheless, the study has important implications owing to its novelty. Considering the increasing use of online pharmacies in the country, the results of this study call for formulation and stringent implementation of regulations for online pharmacies in India, to ensure the safe use of medicines by the consumer. The criteria used in the study like shipment within the territory of the country, availability of a retail license, display of contact address, display of privacy policy, the requirement of prescription, confidentiality policy etc. can provide a good di- 
rection to formulate the regulatory guidelines for online pharmacies in India.

\section{CONCLUSION}

Regulatory bodies should be more vigilant and take stringent actions to certify and monitor all online pharmacies within their purview. Consumer education about the appropriate use of online pharmacies is required.

\section{ACKNOWLEDGEMENT}

The study was carried out under the guidance of Dr. Mira K. Desai, former professor and head, Department of Pharmacology, B.J. Medical College, Ahmedabad.

\section{CONFLICT OF INTEREST}

The authors declare no conflict of interest.

\section{ABBREVIATIONS}

OP: Online Pharmacy; VIPPS: Verified Internet Pharmacy Practice Sites; NABP: National Association of Boards of Pharmacy; GPhC: General Pharmaceutical Council; CIPA: Canadian International Pharmacy Association.

\section{REFERENCES}

1. Fung $\mathrm{CH}$, Woo HE, Asch SM. Controversies and legal issues of prescribing and dispensing medications using the internet. Mayo Clin Proc. 2004;79(2):188-94.

2. Orizio G, Gelatti U. Public e-health and new scenarios in terms of risks and opportunities: a specific focus on cyber pharmacies. Social Semiotics. 2010;20(1):29-41.

3. Desai C. Online pharmacies: A boon or bane?. Indian J Pharmacol. 2016;48(6):615-6.

4. Gordon SM, Forman RF, Siatkowski C. Knowledge and use of the internet as a source of controlled substances. Journal of Substance Abuse Treatment. 2006;30(3):271-4

5. Anand A, Sethi N, Sharon G, Mathew G, Songara R, Kumar P. Internet Phar macy: Need to be implemented in India. Chronicles of Young Scientists. 2010;1(1):16-25
6. World Health Organization. Internet pharmacies: advantages and risks. WHO Drug Information. 2001;15(3-4):149. Available on: http://apps.who.int/medicinedocs/en/d/Jh2989e/2.html

7. Oliver AJ. Internet pharmacies: regulation of a growing industry. J Law Med Ethics. 2000;28(1):98-101.

8. Thompson CA. Internet-based prescribing and dispensing trouble medical and pharmacy boards. Am J Health Syst Pharm. 1996;56:500-1.

9. National Association of Boards of Pharmacy (NABP). Criteria and standards. Available from: https://nabp.pharmacy/programs/vipps/criteria-standards/

10. General Pharmaceutical Council (GPhC). Guidance for registered pharmacies providing pharmacy services at a distance, including on the internet. Available from: https://www.pharmacyregulation.org/sites/default/files/guidance_for registered_pharmacies_providing_pharmacy_services_at_a_distance_including_on_the_internet_april_2015.pdf

11. Zehra F, Naqvi AB, Tasneem S, Ahmad R, Ahmad N, Shamsi AZ, et al. Brand versus generic dispensing trend for ciprofloxacin $500 \mathrm{mg}$, levofloxacin $500 \mathrm{mg}$ and moxifloxacin 400mg (oral dosage forms) among pharmacies of Karachi, Pakistan. Int J Pharm Investig. 2017;7(2):70-6.

12. Alwon BM, Solomon G, Hussain F, Wright DJ. A detailed analysis of online pharmacy characteristics to inform safe usage by patients. Int J Clin Pharm. 2015;37(1):148-58.

13. Bessell TL, Silagy CA, Anderson JN, Hiller JE, Sansom LN. Quality of global e-pharmacies: can we safeguard consumers?. Eur J Clin Pharmacol. 2002;58(9):567-72.

14. Orizio G, Schulz P, Domenighini S, Caimi L, Rosati C, Rubinelli S, et al. Cyberdrugs: a cross-sectional study of online pharmacies characteristics. Eur J Public Health. 2009;19(4):375-7.

15. Mainous AG, Everett CJ, Post RE, Diaz VA, Hueston WJ. Availability of antibiotics for purchase without a prescription on the internet. Ann Fam Med. 2009:7(5):431-5

16. Jena AB, Goldman DP, Foster FE, Califano JA. Prescription medication abuse and ill-legitimate internet-based pharmacies. Ann Intern Med. 2011;155(12):848-50.

17. Quon BS, Firszt R, Eisenberg M. A comparison of Brand-name drug prices between Canadian-based internet pharmacies and major US drug chain pharmacies. Ann Intern Med. 2005;143(6):397-403.

18. Das SC, Mandal M, Mandal SC. A critical study on availability and price variation between different brands: Impact on access to medicines. Indian $\mathrm{J}$ of Pharm Sci. 2007;69(1):160-63.

19. Kamath L, Satish G. Cost variation analysis of antihypertensive drugs available in Indian market: An economic perspective. IJPSR. 2016;7(5):2050-6.

20. Hansen RA, Dusetzina SB, Dominik RC, Gaynes BN. Prescription refill records as a screening tool to identify anti-depressant non-adherence. Pharmacoepidemiol Drug Saf. 2010;19(1):33-7.

21. Holmes ER, Desselle SP, Nath DM, Markuss JJ. Ask the pharmacist: An analysis of online drug information services. Ann Pharmacother. 2005;39(4):662-7.

Article History: Submission Date : 06-11-2018; Revised Date : 15-01-2019; Acceptance Date : 17-02-2019.

Cite this article: Parikh CD, Desai CK, Shah MK, Mishra VR. An Evaluation of Online Pharmacies for Compliance to Regulatory Criteria and Price Variation of Listed Medicines. J Young Pharm. 2019;11(2):207-12. 